\author{
Marquette University \\ e-Publications@Marquette
}

$6-20-2019$

\title{
Experimental study of hybrid strengthening technique using carbon fiber laminates and steel plates for reinforced concrete slabs
}

Xiaohong Zheng

South China University of Technology

Baolin Wan

Marquette University, baolin.wan@marquette.edu

Peiyan Huang

South China University of Technology

Jinlin Huang

South China University of Technology

Follow this and additional works at: https://epublications.marquette.edu/civengin_fac

Part of the Civil Engineering Commons

\section{Recommended Citation}

Zheng, Xiaohong; Wan, Baolin; Huang, Peiyan; and Huang, Jinlin, "Experimental study of hybrid strengthening technique using carbon fiber laminates and steel plates for reinforced concrete slabs" (2019). Civil and Environmental Engineering Faculty Research and Publications. 239.

https://epublications.marquette.edu/civengin_fac/239 
Marquette University

e-Publications@Marquette

\section{Civil, Construction and Environmental Engineering Research and Publications/College of Engineering}

This paper is NOT THE PUBLISHED VERSION; but the author's final, peer-reviewed manuscript. The published version may be accessed by following the link in the citation below.

Construction and Building Materials, Vol. 210 (June 20, 2019): 324-337. DOI. This article is (C) Elsevier and permission has been granted for this version to appear in e-Publications@Marquette. Elsevier does not grant permission for this article to be further copied/distributed or hosted elsewhere without the express permission from Elsevier.

\section{Experimental study of hybrid strengthening technique using carbon fiber laminates and steel plates for reinforced concrete slabs}

Xiaohong Zheng

School of Civil Engineering and Transportation, South China University of Technology, Guangzhou 510640, China

Baolin Wan Department of Civil, Construction and Environmental Engineering, Marquette University, Milwaukee, WI

Peiyan Huang School of Civil Engineering and Transportation, South China University of Technology, Guangzhou 510640, China

Jinlin Huang

College of Water Conservancy and Civil Engineering, South China Agriculture University, Guangzhou 510642, China 


\section{Abstract}

External bonding (EB) technique has been used widely to strengthen reinforced concrete (RC) structures in civil engineering over several decades. Steel and fiber reinforced polymers (FRP) are the two most common materials used for strengthening RC structures. Although each material has its advantages for EB application, they also have their own weaknesses. Steel plates are heavy and poor in corrosion resistance, and the thickness of steel plates is also limited due to lack of shape flexibility for strengthening RC structures. The EB-FRP technique is restricted for broader applications because the bond interface is the weakest link in such retrofitted or strengthened concrete members, resulting in sudden and brittle debonding failure, and the strength of FRP has not been fully utilized. To overcome these weaknesses, an innovative strengthening method combining FRP and steel materials was explored in this research. Carbon fiber laminates (CFL) and thin steel plates (SP) were combined in different ways to determine the most effective hybrid strengthening configuration. A total of nineteen RC slabs strengthened by different configurations were tested under four-point bending. Failure modes, load versus deflection curves, strains of internal reinforcement bars, CFL and SP, and stiffness of the strengthened specimens were analyzed. The test results proved that the CFL-SP hybrid strengthening technique was effective. The average maximum increases in flexural capacity and stiffness were $204.2 \%$ and $91 \%$ over the control slab, respectively. In addition, the cracking and steel yielding loads of slabs strengthened with CFLSP composite material were higher than those of slabs strengthened by FRP or steel plate only. By combining with steel plate, FRP material was used more efficiently and the stiffness of the strengthened RC slabs was improved. The overlap-type hybrid configuration of bonding CFL as inner plates while steel as outer plates was proved as the most effective hybrid strengthening method within all configurations tested in this research.

\section{Keywords}

External bonding (EB), Carbon fiber laminate (CFL), Steel plate (SP), Hybrid strengthening, RC slab, Flexural capacity, Flexural stiffness

\section{Introduction}

Rehabilitation and strengthening of deteriorated reinforced concrete (RC) structures have attracted much attention in recent decades [34], [10]. Among various strengthening methods, external bonding (EB) technique has been widely used due to several advantages such as low cost, easy construction on site, little disturbance of the use of the structure during construction, and little effect on the original structural dimensions. Steel plates and fiber reinforced polymers (FRP) are the two most common plated materials in civil engineering which are bonded to the tension face to strengthen RC flexural elements. Extensive researches [19], [8], [32], [27], [39], [24], [37] have been conducted, and most of them focused on one type of strengthening material.

Epoxy-bonded steel plates can successfully increase the ultimate flexural capacity and the stiffness of the strengthened structure, delay the appearance of first crack, and reduce the crack width of the RC structures [21], [32], [16], [4]. The major drawbacks of EB-steel plate technique are the corrosion of the steel plate and the premature failure due to plate end debonding of steel plate and shear, which prevent the strengthened member to obtain higher flexural capacities. To eliminate premature shear failure of flexurally strengthened slabs, steel bars with diameter of $8 \mathrm{~mm}$ and length of $140 \mathrm{~mm}$ were used as the embedded connectors and inserted in adhesive filled holes with diameter of $16 \mathrm{~mm}$ in the shear span of the slab. The experimental results proved that embedded connectors and end anchors can completely prevent premature shear failure as well as the debonding of steel plate of the strengthened RC slab [5]. The failure had shown ductile mode rather than brittle. Another drawback of EB-steel plate technique is that the thickness of steel plates is limited because of its inflexibility. It is difficult to bond thick steel plates to irregular or curved 
surface of structures [28]. In general, the maximum thickness of steel plates for strengthening concrete structures is less than $6 \mathrm{~mm}$ [21], [32], [22]. Therefore, steel plates are used less for strengthening concrete structures in recent years due to these shortcomings.

Over the past three decades, fiber reinforced polymer (FRP) composite materials have gradually replaced steel plates to repair concrete structures because of their superior properties [8], [23], [34], [25], [38]. However, the brittle failure such as cover delamination [13], [30] and premature FRP debonding [36], [6], [33] makes the strengthening system inefficient. The allowable strain level in EB-FRP is limited by design guidelines and standards ( $\mathrm{ACl} 2017$ ) [1], and it can be as low as $10 \%-25 \%$ of the material rupture strain [17]. To prevent or delay the process of debonding failure, different anchorages such as bolts [15], FRP anchors [31], and FRP strips or sheet [9], [12] were developed. Compared to steel plate, it is more difficult to anchor FRP because FRP laminates do not have sufficient bearing strength at the anchor location [35]. In addition to the brittle failure, the overall bending stiffness of FRP strengthened beams cannot be guaranteed due to the low elastic modulus and thin thickness of FRP to keep the shape flexibility. Therefore, the EB-FRP strengthened structure suffers excessive deflections and wide cracks that affect its serviceability [36], [13], [29].

To solve these problems of using single material, the concept of combining steel plate with FRP (hybrid strengthening system) may be a practical solution considering that FRP and steel can compensate each other on the material properties. Steel is heavy, easy to corrode and inflexible in shape. FRP is light weight, has excellent corrosion resistance and shape flexibility. On the other hand, FRP is brittle, while steel has good ductility. Therefore, a new hybrid strengthening technique combining carbon fiber laminate (CFL) and steel plate $(\mathrm{SP})$ is proposed in this study. Very limited research on the hybrid strengthening technique combining FRP and steel can be found in the literature. A combination of FRP and steel rebars has been proposed and adopted in RC beams. Several studies [29], [18], [26], [7] showed that the contribution of steel rebars to FRP rebars in concrete beams improved beam ductility and eliminated the unfavorable brittle failure of the concrete beam. Li et al. [20] bonded both CFRP strips and steel sheets to strengthen four two-way RC slabs. Their experimental results proved the effectiveness of this hybrid strengthening technique. The maximum increase in flexural strength of the hybrid strengthened slab was $221.1 \%$ over the unstrengthened slab. In addition, the CFRP-steel hybrid strengthened slab exhibited more ductility than the CFRP-strengthened slab. However, the strains of CFRP and steel were absent in their reports. Moreover, only two bolt fasteners at the end of steel plates were used to anchor FRP, and brittle debonding failure still happened in the strengthened beams [20]. Therefore, more researches are needed for FRP-steel hybrid strengthening technique.

To overcome the weakness of the strengthening method by externally bonding single material, this paper proposes a new hybrid strengthening technique combining carbon fiber laminate (CFL) and steel plate (SP). The aim of this technique is to increase the strength and stiffness of flexural RC members, and to solve the anchoring problem of EB-FRP to enhance the ductility of the strengthened RC members. A series of experiments consisting of nineteen specimens were conducted to evaluate the effectiveness of the CFL-steel hybrid strengthening technique. CFL and SP materials were combined to strengthen RC slabs in parallel and overlap configurations to study which configuration is more efficient. Failure modes and load versus deflection relationships were studied carefully to evaluate the effectiveness of the hybrid technique. Strain data, stiffness and crack development were analyzed to explore the strengthening mechanism with the CFL-SP composite.

\section{Experimental program}

\subsection{RC slabs}

A total of nineteen RC one-way slabs were tested under four-point bending in this study. All slabs had a crosssection of 120 -mm-thick $\times 600-\mathrm{mm}$-wide $\times 2500-\mathrm{mm}$-long, and the clear span between the centers of two 
supports was $2200 \mathrm{~mm}$ as shown in Fig. 1. Each slab was reinforced with $6 \varphi 8$ (nominal diameter of $8 \mathrm{~mm}$ ) smooth steel bars in the tension zone and $6 \varphi 8$ smooth steel bars in the compression zone as shown in Fig. 1 b. The tension steel reinforcement ratio in all slabs were $0.56 \%$, which was within the minimum $(0.20 \%)$ and maximum (4.39\%) amounts of reinforcement ratio required by China's design codes [11]. In order to avoid shearing failure, the shear reinforcements were designed in the slabs. Each slab included two types of $\varphi 8$ stirrups as shear reinforcement, one enclosing all longitudinal reinforcements (marked as (2) in Fig. 1c) and the other enclosing the four longitudinal reinforcements at each side (marked as (3) in Fig. 1c). The shear stirrups were designed with various spacings along the span. The stirrups were installed with a center-to-center spacing of $50 \mathrm{~mm}$ in the regions near the supports according to the construction requirement by China's design codes (GB 50010-2014) [11]. The center-to-center spacings of stirrups were changing form $100 \mathrm{~mm}$ to $200 \mathrm{~mm}$ along the span (Fig. 1a).

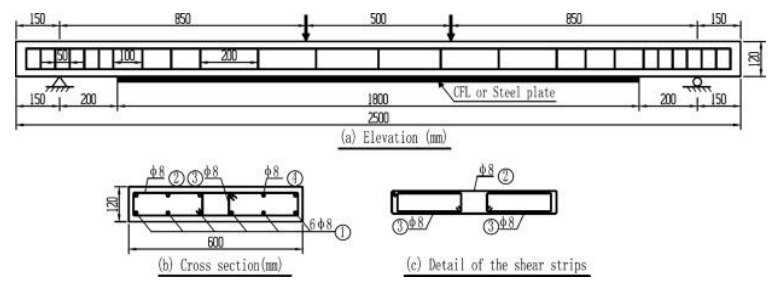

Fig. 1. Dimensions and reinforcement details of RC slabs.

\subsection{Test matrix}

EB strengthening material types and their hybrid configurations are the key parameters in this study. The details of the test matrix are listed in Table 1. Among the nineteen concrete slabs, two specimens were control slabs without any strengthening named as F-1 and F-2. The remaining seventeen slabs were divided into six groups according to different externally bonded material types and their quantities, and hybrid configurations as listed in Table 1.

Table 1. Test matrix details.

\begin{tabular}{|c|c|c|c|c|c|}
\hline Group & Slab No. & EB-materials & $\begin{array}{l}\text { Hybrid } \\
\text { configuration }\end{array}$ & Anchor & $\begin{array}{l}\text { Equivalent } \\
\text { reinforcement ratio }\end{array}$ \\
\hline $\mathrm{F}$ & $F-1, F-2$ & No strengthening & & & $0.56 \%$ \\
\hline$A$ & $\begin{array}{l}A-1, A-2, A- \\
3\end{array}$ & $3 \times 50 \mathrm{~mm}$ steel plates & single & bolts & $1.39 \%$ \\
\hline B1 & $\begin{array}{l}\text { B1-1, B1-2, } \\
\text { B1-3 }\end{array}$ & $2 \times 75 \mathrm{~mm} \mathrm{CFL}$ & single & CFL strips & $1.04 \%$ \\
\hline B2 & B2-1, B2-2 & $6 \times 50 \mathrm{~mm} \mathrm{CFL}$ & single & CFL strips & $1.67 \%$ \\
\hline$C$ & $\begin{array}{l}\mathrm{C}-1, \mathrm{C}-2, \mathrm{C}- \\
3\end{array}$ & $\begin{array}{l}3 \times 50 \mathrm{~mm} \mathrm{SP} \\
+2 \times 75 \mathrm{~mm} \mathrm{CFL} \\
\end{array}$ & parallel-type & $\begin{array}{l}\text { bolts, CFL } \\
\text { strips }\end{array}$ & $2.01 \%$ \\
\hline D1 & $\begin{array}{l}\text { D1-1, D1-2, } \\
\text { D1-3 }\end{array}$ & $\begin{array}{l}3 \times 50 \mathrm{~mm} \mathrm{SP} \\
+3 \times 50 \mathrm{~mm} \mathrm{CFL}\end{array}$ & overlap-type & bolts & $2.01 \%$ \\
\hline D2 & $\begin{array}{l}\text { D2-1, D2-2, } \\
\text { D2-3 }\end{array}$ & $\begin{array}{l}3 \times 50 \mathrm{~mm} \mathrm{SP} \\
+3 \times 50 \mathrm{~mm} \mathrm{CFL}\end{array}$ & overlap-type & $\begin{array}{l}\text { bolts, CFL } \\
\text { strips }\end{array}$ & $2.01 \%$ \\
\hline
\end{tabular}

All steel plates were $50 \mathrm{~mm}$ wide. The width of CFL strips was $50 \mathrm{~mm}$ except for the specimens in groups B1 and C, which was $75 \mathrm{~mm}$. The thickness and length of CFL strips were $0.226 \mathrm{~mm}$ and $1800 \mathrm{~mm}$, respectively, and those of steel plates were $3.7 \mathrm{~mm}$ and $1600 \mathrm{~mm}$, respectively. 
All CFL strips and steel plates were bonded to the tensile faces of the specimens. There were two different anchor methods: steel bolts and CFL strips. Steel bolts with space of $375 \mathrm{~mm}$ were used to anchor steel plates, while CFL strips were bonded at the end of CFLs as shown in Fig. 2.

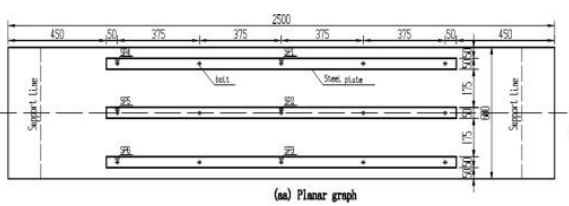

(a) A-1, A-2, A-3

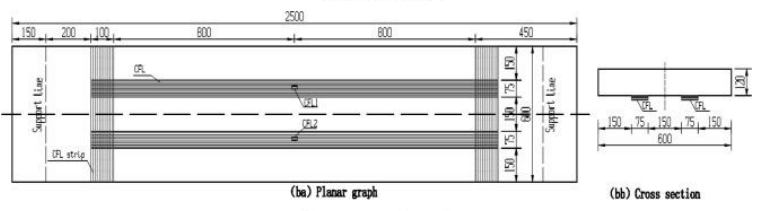

(b) B1-1, B1-2, B1-3

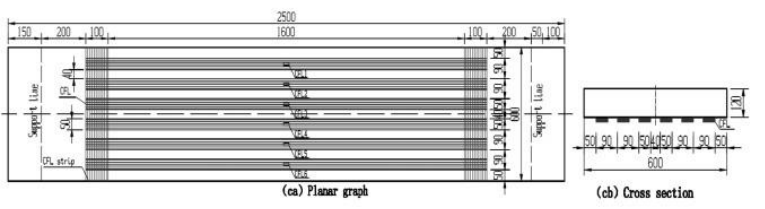

(c) B2-1, B2-2

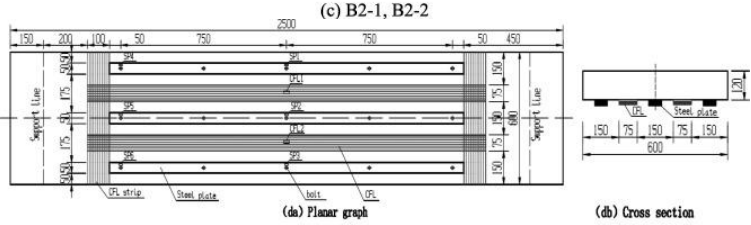

(d) $\mathrm{C}-1, \mathrm{C}-2, \mathrm{C}-3$

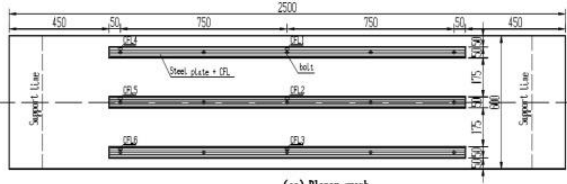

(ea) Planar grape

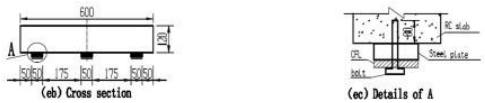

(e) D1-1, D1-2, D1-3
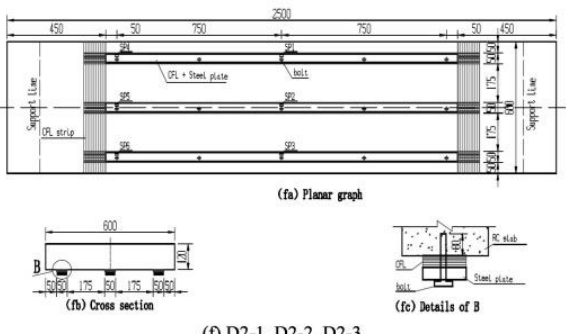

(f) D2-1, D2-2, D2-3

Fig. 2. Strengthening details and strain gauge locations (unit: $\mathrm{mm}$ ) ( steel bolt, $\mathbf{a}$ strain gauges for CFL named CFL1 CFL6, or strain gauges for steel plates named SP1 SP6).

To compare the strengthening effects of CFL strip and steel plate, groups A and B were strengthened with single material. Group A specimens (Fig. 2a) were bonded with three 50-mm-wide steel plates with bolt anchors. Group B included two sets of specimens with different amounts of CFLs with CFL strip anchors at ends. Two CFLs with width of $75 \mathrm{~mm}$ were bonded symmetrically to the centerline of the slabs in group B1 (Fig. 2b), while six 50$\mathrm{mm}$-wide CFLs were bonded to the specimens in group B2 as shown in Fig. 2c.

Groups $C$ and $D$ were slabs strengthened with combination of steel and CFL materials. The main difference between groups $C$ and $D$ was the hybrid configuration. In group $C$, three $50-\mathrm{mm}$-wide steel plates and two 75 - 
mm-wide CFL strips were bonded in parallel and separately as shown in Fig. $2 \mathrm{~d}$. In group $\mathrm{D}$, three 50-mm-wide steel plates and three 50-mm-wide CFL strips were bonded as one on top of the other. The total width of three 50-mm-wide CFLs was equivalent to that of two 75-mm-wide CFLs. Therefore, groups $\mathrm{C}$ and $\mathrm{D}$ had same amount of strengthening materials to study the effect of different hybrid configurations. For group D1, steel plates were bonded to the tension face of the RC slab first, then CFL strips were bonded on the outer surface of steel plates as shown in Fig. 2ec. The bonding sequence in group D2 was in reverse, i.e., CFL strips were bonded to concrete surface first and the steel plates were then bonded to CFLs. In group D1, only bolts were used to anchor the steel plates. In group D2, besides of the bolts, the inner CFL was longer than steel plate, and additional CFL strips as anchors were bonded in transverse direction at the ends of the longitudinal CFLs as shown in Fig. 2f. The detail drawings of partial cross-sections of D1 and D2 are shown in Fig. 2ec and 2fc, respectively.

In summary, there were two control slabs (F-1, F-2) without strengthening, three specimens (Group A) with single EB-Steel, five specimens (Group B) strengthened with single EB-CFL, and nine specimens (Group C, D) with CFL-SP composites. Two anchor methods were used in this study. CFL strips were bonded at the end of EB-CFL (Groups B, C and D2), and expansion bolts were used to anchor the steel plates or CFL-SP composites along the plates in 12 specimens (Group A, C, D).

\subsection{Material properties}

All slabs were cast from same batch of ready-mixed concrete. The 28-day compressive strength and modulus of elasticity of $150 \mathrm{~mm} \times 150 \mathrm{~mm} \times 150 \mathrm{~mm}$ cubic concrete specimens were $38.5 \mathrm{MPa}$ and $31.3 \mathrm{GPa}$ on average, respectively. The Grade R235 steel reinforcement bars used in slabs were smooth and round. The mechanical properties of the steel bars were determined by direct tensile tests (ASTM A706 2004) [2]. The mean yielding strength and modulus of elasticity of the longitudinal steel reinforcement were 325.0 MPa and 204.2 GPa, respectively. The 3.7-mm-thick steel plate used for externally bonding to slabs was Grade Q345-C steel with nominal yielding and ultimate strengths of 408.5 and $660 \mathrm{MPa}$, respectively.

The carbon fiber laminate (CFL) used in this study was pre-saturated laminates fabricated by T700-12k carbon fibers [14]. The thickness of one layer of dry CFL was $0.226 \mathrm{~mm}$. CFL composite coupons were fabricated by saturating dry CFL in epoxy and cured in room temperature for 7 days, then tested in tension by following [3]. The average ultimate tensile strength and elastic modulus of the CFL composite with $0.226 \mathrm{~mm}$ equivalent thickness were 4305.0 MPa and 224.0 GPa, respectively.

The adhesive used for bonding CFL strips to the tension face of the slabs was a two-part epoxy mixed in a ratio of 1:1 by volume and cured at room temperature. The shear and tensile strengths of the epoxy adhesive supplied by the manufacturer are $14 \mathrm{MPa}$ and $40 \mathrm{MPa}$, respectively. The two-part epoxy for attaching steel plate to concrete has manufacturer-reported shear strength of $21.0 \mathrm{MPa}$.

M6 expansion bolts were used to anchor the steel plates, which penetrated to a depth of $80 \mathrm{~mm}$ in concrete. The manufacturer-reported shear and tension capacities of the bolt are $1.8 \mathrm{kN}$ and $2.4 \mathrm{kN}$, respectively. The mechanical properties of all materials used in this research are summarized in Table 2.

Table 2. Summary of material properties.

\begin{tabular}{|l|l|l|l|}
\hline Materials & Type & Material properties & Values \\
\hline Concrete & C35 & 28-day cubic compressive strength (MPa) & 38.5 \\
\hline & & Elastic modulus (GPa) & 31.3 \\
\hline Steel bars & R235 & Yield strength (MPa) & 325.0 \\
\hline & & Modulus of elasticity (GPa) & 204.2 \\
\hline Steel plate & Q345-C & Yield strength (MPa) & 408.5 \\
\hline & & Modulus of elasticity (GPa) & 206.0 \\
\hline
\end{tabular}




\begin{tabular}{|l|l|l|l|}
\hline & & ultimate strength (MPa) & 660.0 \\
\hline CFL & TB-25 & Tensile strength (MPa) & 4305.0 \\
\hline & & Nominal modulus of elasticity (GPa) & 224.0 \\
\hline & & Poisson's ratio & 0.22 \\
\hline Adhesive for bonding CFL & Two-part epoxy & Shear strength (MPa) & 14.0 \\
\hline & & Tensile strength (MPa) & 40.0 \\
\hline Adhesive for bonding steel & Two-part epoxy & Shear strength (MPa) & 21.0 \\
\hline Bolt & M6 & Tensile strength (MPa) & 84.9 \\
\hline & & Shear strength (MPa) & 63.7 \\
\hline
\end{tabular}

In order to compare the performance of the different slabs tested, areas of CFL and steel plates are converted into an equivalent the area of longitudinal reinforcement by keeping their design capacities, $F$, identical as shown in Eq. (1).(1) $\mathrm{F}=\sigma S A s=\sigma C F L A C F L=\sigma s p A S P$ where $\sigma_{s}, \sigma_{C F L}$, and $\sigma_{s p}$ are the yield strength of steel rebar, the ultimate strength of $\mathrm{CFL}$, and the yield strength of steel plate, respectively. They are $325.0 \mathrm{Mpa}, 4305.0 \mathrm{Mpa}$, and $408.5 \mathrm{Mpa}$, respectively. $A_{s}$ is the equivalent steel rebar area for CFL or steel plate. $A_{C F L}$ and $A_{s p}$ are the total cross-sectional areas of CFL and steel plate in the specimen. The equivalent steel rebar area of CFL and SP in each group of specimens was calculated by using Eq. (1). They were added to the internal steel rebar area to obtain the equivalent reinforcement ratio for each group as shown in Table 3. 
Table 3. Summary of the experimental results.

\begin{tabular}{|c|c|c|c|c|c|c|c|c|c|c|}
\hline Slab & $\begin{array}{l}\text { Ulimate } \\
\text { Load }\end{array}$ & & Ulimate deflection & Stiffness & & $\begin{array}{l}\text { Maximum } \\
\text { strain }\end{array}$ & & & $\begin{array}{l}\text { Cracking } \\
\text { load (kN) }\end{array}$ & failure mode \\
\hline & $\mathrm{Pu}(\mathrm{kN})$ & $\Delta \mathrm{P} / \mathrm{PFa}(\%)$ & $\delta \mathrm{u}(\mathrm{mm})$ & $\begin{array}{l}\mathrm{S} \\
(\mathrm{kN} / \mathrm{mm})\end{array}$ & $\Delta \mathrm{S} / \mathrm{SFb}(\%)$ & $\varepsilon C(\mu \varepsilon)$ & $\varepsilon C F L(\mu \varepsilon)$ & $\varepsilon S P(\mu \varepsilon)$ & & \\
\hline $\mathrm{F}-1$ & 31.00 & 0.00 & 56.80 & 3.23 & & -1067 & & & 10.00 & flexural failure \\
\hline $\mathrm{F}-2$ & 30.80 & 0.00 & 57.52 & 3.56 & & -495 & & & 8.00 & flexural failure \\
\hline$A-1$ & 66.00 & 113.59 & 30.00 & 6.20 & 82.29 & -1291 & & 4688 & 30.00 & shear failure \\
\hline$A-2$ & 69.00 & 123.30 & 37.60 & 6.34 & 86.41 & -1079 & & 12,410 & 28.00 & shear failure \\
\hline$A-3$ & 69.00 & 123.30 & 32.00 & 6.12 & 79.88 & -1902 & & 6176 & 30.00 & shear failure \\
\hline B1-1 & 52.00 & 68.28 & 40.15 & 3.19 & -6.09 & n.a. & 10,079 & & 20.00 & $\begin{array}{l}\text { CFL rupture near } \\
\text { midspan }\end{array}$ \\
\hline B1-2 & 52.50 & 69.90 & 41.20 & 3.60 & 5.91 & -1443 & 11,129 & & 20.00 & $\begin{array}{l}\text { CFL rupture near } \\
\text { midspan }\end{array}$ \\
\hline B1-3 & 51.00 & 65.05 & 43.11 & 3.86 & 13.50 & -2422 & 11,128 & & 16.00 & $\begin{array}{l}\text { CFL rupture near } \\
\text { midspan }\end{array}$ \\
\hline B2-1 & 77.00 & 149.19 & 56.37 & 3.65 & 7.47 & -1893 & 9577 & & 15.00 & $\begin{array}{l}\text { CFL rupture near } \\
\text { midspan }\end{array}$ \\
\hline B2-2 & 70.00 & 126.54 & 55.17 & 4.68 & 37.56 & -1220 & 8637 & & 16.00 & $\begin{array}{l}\text { CFL rupture near } \\
\text { midspan }\end{array}$ \\
\hline C-1 & 82.00 & 165.37 & 41.94 & 6.26 & 84.06 & -1029 & 6975 & 18,426 & 36.00 & $\begin{array}{l}\text { CFL rupture near } \\
\text { midspan / SP } \\
\text { debonding from the } \\
\text { end }\end{array}$ \\
\hline$C-2$ & 70.00 & 126.54 & 45.41 & 5.98 & 75.76 & -1048 & 5011 & 17,548 & 35.00 & $\begin{array}{l}\text { CFL rupture near } \\
\text { midspan / SP } \\
\text { debonding from the } \\
\text { end }\end{array}$ \\
\hline$C-3$ & 85.00 & 175.08 & 53.19 & 5.96 & 75.29 & -907 & 11,233 & 10,330 & 34.00 & $\begin{array}{l}\text { CFL rupture near } \\
\text { midspan/ Shear / SP } \\
\text { debonding from the } \\
\text { end }\end{array}$ \\
\hline D1-1 & 78.00 & 152.43 & 38.55 & 6.79 & 99.59 & -1092 & 9207 & & 35.00 & $\begin{array}{l}\text { SP debonding from the } \\
\text { end }\end{array}$ \\
\hline D1-2 & 81.20 & 162.78 & 46.80 & 6.16 & 81.12 & n.a & 8469 & & 33.00 & $\begin{array}{l}\text { SP debonding from the } \\
\text { end }\end{array}$ \\
\hline
\end{tabular}




\begin{tabular}{|l|l|l|l|l|l|l|l|l|l|l|}
\hline D1-3 & 74.00 & 139.48 & 48.00 & 6.33 & 86.29 & -1066 & 9083 & & 30.00 & $\begin{array}{l}\text { SP debonding from the } \\
\text { end }\end{array}$ \\
\hline D2-1 & 87.00 & 181.55 & 45.08 & 5.80 & 70.71 & n.a. & & 13,615 & $\begin{array}{l}30.00 \\
\text { Debonding from the } \\
\text { end /concrete crush }\end{array}$ \\
\hline D2-2 & 95.00 & 207.44 & 52.68 & 6.93 & 103.94 & -1752 & & 16,341 & 35.00 & $\begin{array}{l}\text { Debonding from the } \\
\text { end /concrete crush }\end{array}$ \\
\hline D2-3 & 100.00 & 223.62 & 48.36 & 6.76 & 98.91 & -1299 & & 19,291 & 30.00 & $\begin{array}{l}\text { Debonding from the } \\
\text { end /concrete crush }\end{array}$ \\
\hline
\end{tabular}

Note: Data for the concrete strains of B1-1, D1-2 and D2-1 were not obtained because the strain gauges were damaged during moving and setting up the specimens.

${ }^{a} P_{F}=$ the average ultimate load of control slabs (F-1 and F-2).

${ }^{\mathrm{b}} \mathrm{S}_{\mathrm{F}}=$ the average stiffness of control slabs (F-1 and $\mathrm{F}-2$ ). 


\subsection{Slab preparation and anchor details}

When the concrete was at the age of 28 days, the following procedures were followed to prepare the slabs for bonding the strengthening materials. Firstly, holes for anchor bolts with a diameter of $8 \mathrm{~mm}$ and depth of $80 \mathrm{~mm}$ were drilled in the slab by an electric drill machine at the designed locations (Fig. 2). Secondly, the bonded surface was grinded smoothly with a grinding machine to remove the weak layer of concrete (approximately $1 \mathrm{~mm}$ in depth) until aggregates were exposed. Thirdly, the strengthening materials were prepared. CFL was pre-saturated and fabricated by the T700-12 k carbon fibers. Steel brush was used to remove rust on the top surface of steel plates. Then the holes were drilled in the steel plates corresponding to the location of holes predrilled in the slab. The bonding surface of the steel plates were roughened by an electric grinding machine and cleaned thoroughly with acetone. CFL and SP were cut into the designed length and ready to be bonded.

Prior to bonding procedure, the dust on the bottom of slabs and in the holes was removed by high pressure air, and acetone was used to clean the bonded concrete surface. Epoxy adhesive was hand-mixed according to the manufacturer's instruction. An approximately 1.5-mm-thick layer of adhesive was applied evenly on the bonding surface using a scraper. The CFL was then carefully hand-laid to the bonding surface to achieve a smooth surface. A plastic scraper was used to press the CFL surface to pull the fibers straight and remove the air between the slab surface and the CFL. Special consideration was given to bond the steel plates and CFL-SP composites. To improve the anchorage, epoxy adhesive was injected into the cleaned holes in the slabs, then the bolts were inserted. CFL or steel plates were bonded at the designed locations. Bolts were penetrated through the steel plates and CFL. The fibers in CFL bypassed the bolts without any damages. For the specimens in groups D1 and D2 in which CFL and SP were bonded in overlap-type configurations, epoxy adhesive was applied on the surface of the inner layer of steel plate or CFL after it had cured, then the outer layer (CFL or SP) was installed. Fig. 3 shows different groups of strengthened slabs. After bonding operations were completed, the strengthened slabs were cured for more than one week in laboratory conditions before testing.

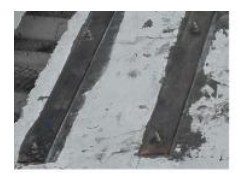

(a) Group A

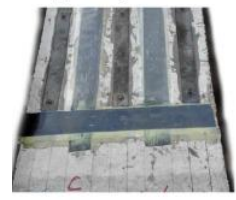

(d) Group C

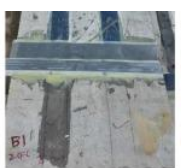

(b) Group B1

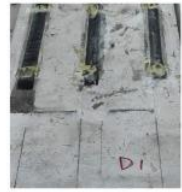

(e) Group D1

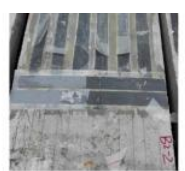

(c) Group B2

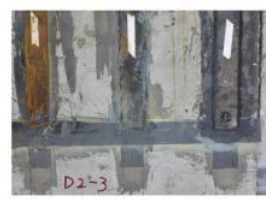

(f) Group D2

Fig. 3. Different anchor at the end of strengthened slabs.

\subsection{Test Set-up and instrumentation}

All slabs were tested under a four-point loading system in this study. A schematic diagram of the experimental set-up and the arrangement of the instrumentation devices is shown in Fig. 4. The load applied to the mid-point of a spreader beam was divided symmetrically into two concentrated loads and applied to the slabs. Specimens were tested in displacement control at a rate of $0.005 \mathrm{~mm} / \mathrm{s}$. 


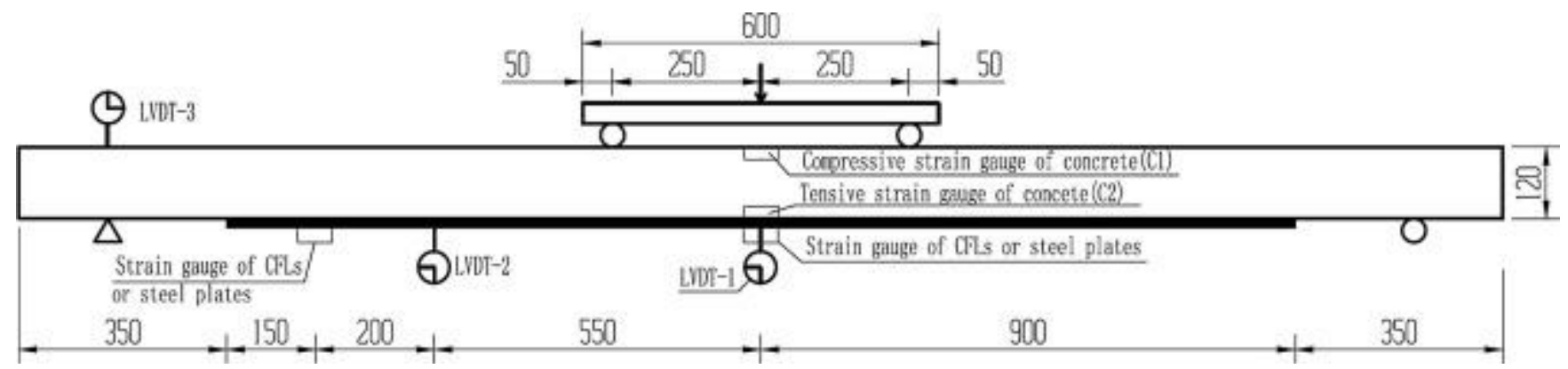

Fig. 4. Test set-up and instrumentation details (unit: $\mathrm{mm}$ ).

During the testing, the deflections at the locations of left support, midspan, and 1/4 span were measured by linear variable displacement transducers (LVDTs) as shown in Fig. 4. Two electric strain gauges (SB1, SB2) were mounted on the internal longitudinal reinforced steel bars at midspan before casting concrete. The strains of concrete at top side (C1) and bottom side (C2) of the midspan section of specimens were measured using strain gauges. Strain gauges were also mounted onto the $\mathrm{CFL}$, steel plates, and composite plates at the midspan and the end of the plates on the specimen tension surface as shown in Fig. 2. The experimental data were recorded using a computer data acquisition system. The crack width was measured by a concrete crack width observation instrument. A typical slab being tested is shown in Fig. 5.

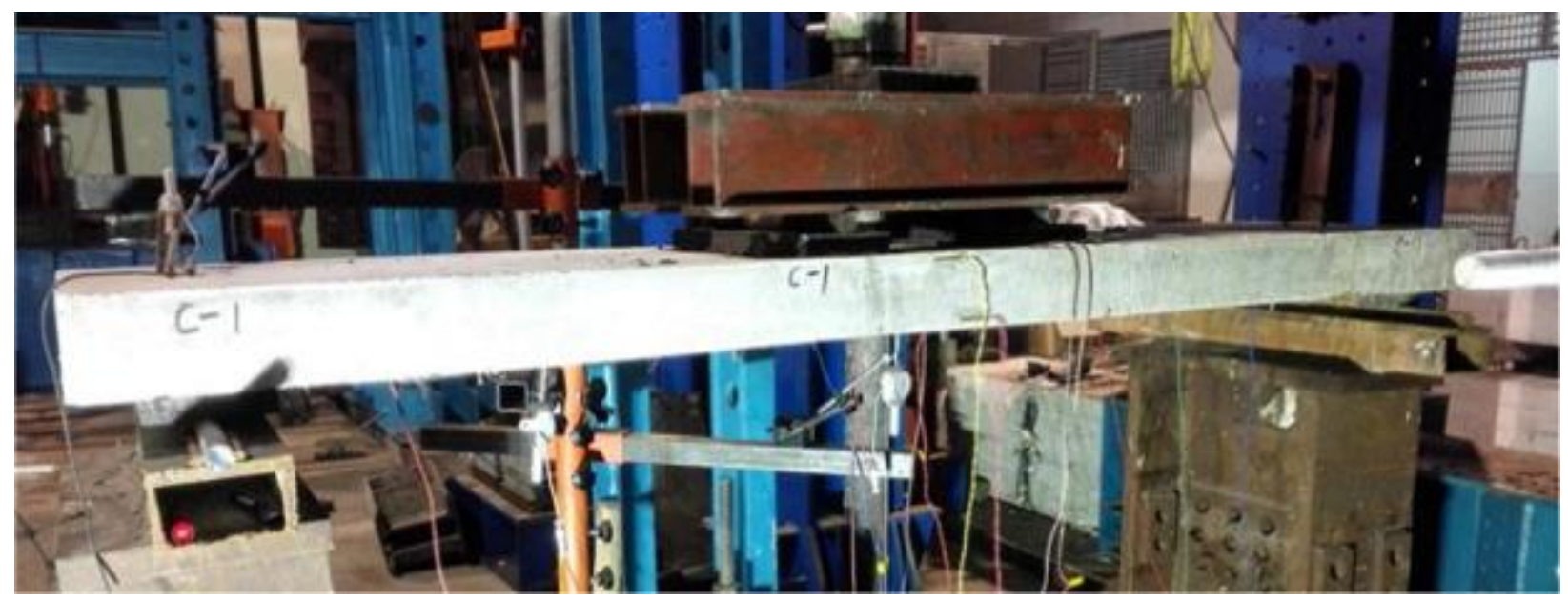

Fig. 5. Typical test in progress.

\section{Result and discussion}

The results of the experimental tests are summarized in Table 3. It clearly shows that the hybrid strengthening method increased the ultimate load and stiffness of the RC slab effectively. The increases of ultimate loads of D2-1, D2-2 and D2-3 over the average ultimate load of the control slabs were $181.6 \%, 207.4 \%$ and $223.6 \%$, respectively. The flexural stiffnesses of D2-1, D2-2 and D2-3 were 70.7\%, 103.9\% and $98.9 \%$ higher than the average flexural stiffness of control slabs. In addition, the cracking loads of the slabs strengthened with hybrid CFL-SP technique were higher than that of the slabs using single EB strengthening method. Compared to the single CFL strengthened slabs (group B2), the maximum increases in flexural strength and stiffness of slabs strengthened by CFL-SP (D2-3) were $36.1 \%$ and $66.4 \%$, respectively.

\subsection{Load versus deflection curves}

The load versus midspan deflection curves are shown in Fig. 6 . Groups $A(3 \times 50 \mathrm{~mm} \mathrm{SP})$ and B1 $(2 \times 75 \mathrm{~mm} \mathrm{CFL})$ are compared with the control slabs without strengthening in Fig. 6a. Groups B2 $(6 \times 50 \mathrm{~mm} \mathrm{CFL}), \mathrm{C}(3 \times 50 \mathrm{~mm}$ 
$\mathrm{SP}+2 \times 75 \mathrm{~mm} \mathrm{CFL})$ and $\mathrm{D}(3 \times 50 \mathrm{~mm} \mathrm{SP}+3 \times 50 \mathrm{~mm} \mathrm{CFL})$ were compared with the control specimens in Fig. $6 b$.

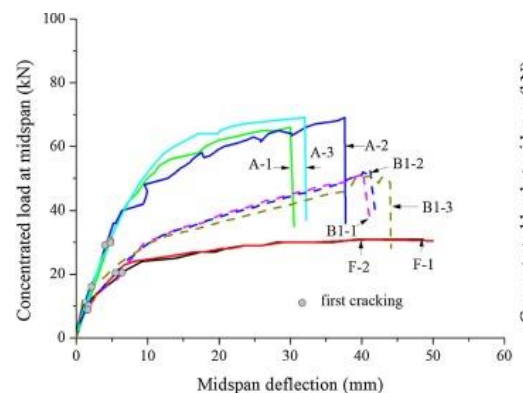

(a) Single EB strengthening method

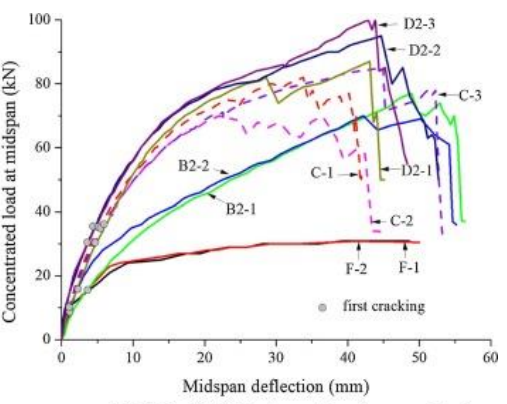

(b) Hybrid EB strengthening method

Fig. 6. Concentrated load at midspan versus midspan deflection.

The first and second changes of the curves' slope were caused by the first cracking in concrete and yielding of the longitudinal steel bars, respectively. The corresponding locations on the load vs deflection curves of the first crack are marked in Fig. 6 . The cracking load for each specimen is shown in Table 3. Slight drops in the curves usually caused by local damage such as local debonding, or bolt damage due to uneven distribution of shearing stress on the interface and the ununiform strength of the bond interface or the bolt. However, the sudden and large drop of the curves indicated failure of the specimens.

Load versus deflection curves of slabs using single strengthening technique are compared with those of nonstrengthened slabs in Fig. 6a. The EB-SP strengthened slabs (group A) had a higher ultimate load, cracking load and flexural stiffness than those of control and CFL strengthened (group B1) slabs. The average ultimate loads for groups A and B1 were $68.0 \mathrm{kN}$ and $51.8 \mathrm{kN}$, respectively, and the average cracking loads of them were 29.3 $\mathrm{kN}$ and $18.7 \mathrm{kN}$, respectively. The average increases in ultimate load for groups A and B1 were $120.1 \%$ and $67.8 \%$ over that of control slabs, respectively. However, stress concentrations at the ends of the steel plates led to premature shear failure with less ductility, which was indicated by the smaller deflection at failure of group $A$ specimens compared to the control specimens.

Compared to the specimens of group B2 strengthened only by CFL, the CFL-SP hybrid strengthened slabs (groups $\mathrm{C}$ and D2) had a significant increase in flexural capacity and stiffness as shown in Fig. $6 \mathrm{~b}$. The average increases in strength of specimens in groups B2, C, D1, and D2 over that of the control slab were $137.9 \%, 55.7 \%, 151.6 \%$ and $204.2 \%$, respectively. The CFL and SP hybrid strengthened slabs had similar flexural stiffness, which was higher than that of slabs strengthened by CFL only (group B2). This means that the limitation to the increase of the stiffness for EB-FRP strengthened concrete members can be overcome successfully by combining with steel plates. The maximum deflections of specimens in groups D2 and B2 with bonding CFL strip anchor were close and larger than those of specimens C-1 and C-2 and specimens in group D1, which indicates that strengthening with CFL anchor technique exhibited better ductility. Specimen C-3 had larger deflection than the other two specimens in group $\mathrm{C}$ because its failure mode was not exactly same as C- 1 and $\mathrm{C}-2$ as described in the following section.

Fig. 7 shows the load versus deflection relationships for slabs of groups D1 (inner SP/outer CFL) and D2 (inner CFL/outer SP) to compare the difference caused by the location of CFL and SP. Obviously, slabs in group D2 experienced higher peak load and deflection than those of slabs in Group D1. The average ultimate load and deflection for Group D2 were 21\% and 9.6\% higher than those of Group D1, respectively. Consequently, the overlap-type with inner CFL and outer SP was proved as the most effective hybrid configuration in this study to strengthen the RC concrete flexural members. For Group D1 slabs bonded with inter SP and outer CFL, the hybrid CFL/SP composite only anchor with bolts. At the end of SP, there was only one bolt to anchor. When it 
was subjected to loading, CFL resisted tension force first, and transferred stress to inner SP only through epoxy interface. Then SP transferred stress to slabs. Brittle debonding happened from the end of SP which caused by the high stress concentration due to insufficient anchor at the end. On the contrary, for group D2, when steel plates were bonded as the outer layer, it resisted tension force first, and transferred stress to inner FRP through interface between CFL and SP. Because the strong bolt anchor action, the stress was transferred to the whole RC slabs by bolts at the same time. Therefore, stress in CFL was less than that in SP. The outer SP and bolts prevented premature debonding failure happened. Because of the excellent ductility of SP, hybrid bonding with inner CFL and outer SP was the most effective and efficient strengthening technique, and obtained highest flexural capacity and larger deformation.

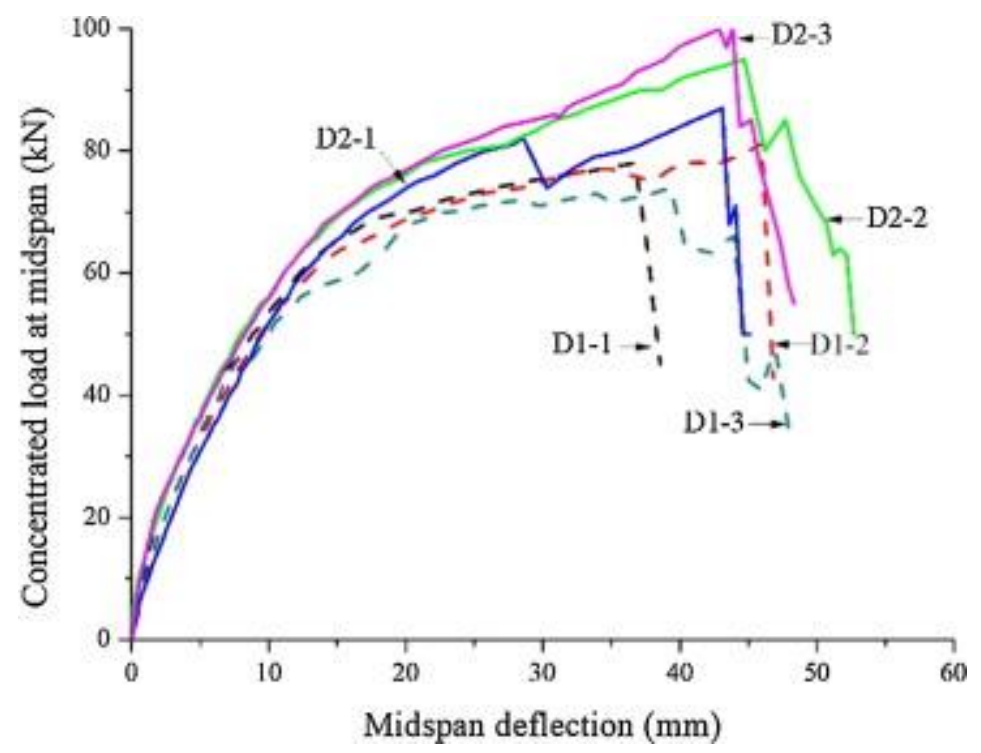

Fig. 7. Comparison of the load-deflection curves between D1 and D2.

\subsection{Slab behavior and failure mode}

The unstrengthened control slabs (F-1, F-2) exhibited a typical ductile flexural failure mode. The first tensile crack of concrete occurred at the loads of $10 \mathrm{kN}$ and $8 \mathrm{kN}$ for F-1 and F-2, respectively. The longitudinal steel reinforcements in these two control specimens were yielded at $25 \mathrm{kN}$ and $24 \mathrm{kN}$, respectively. The slab then deflected extensively. The test was stopped when the midspan deflection was over $50 \mathrm{~mm}$ to protect LVDTs. The maximum width of crack exceeded $2 \mathrm{~mm}$ at that time.

The slabs in group A, which were strengthened by EB steel plates only, presented higher stiffness due to the contributions of the steel plates. They failed as a shear failure mode shown in Fig. 8a caused by the high stress concentration at the end of steel plates. The bolts and bonding were still in good condition when this sudden failure happened. 


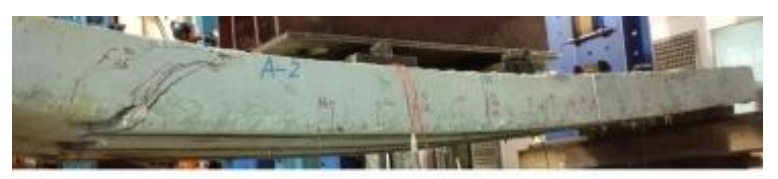

(a) Failure mode of Group A

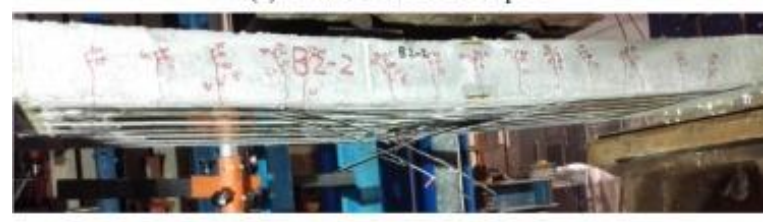

(b) Typical failure mode of Group B

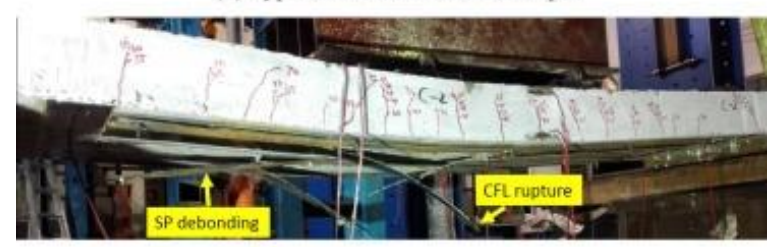

(c) Typical failure mode of Group C

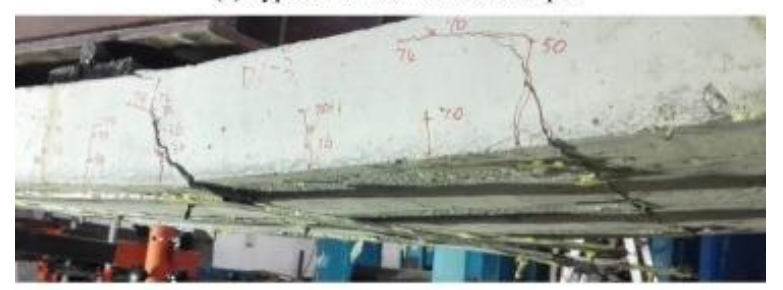

(d) Typical failure mode of Group D1

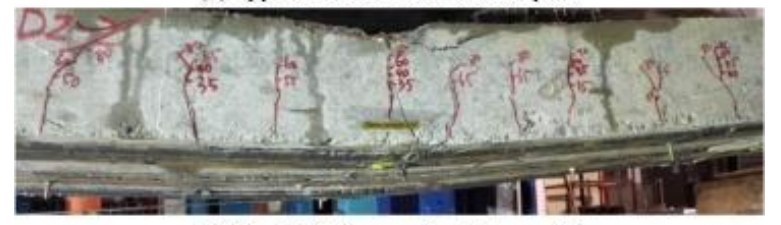

(e) Typical failure mode of Group D2

Fig. 8. Typical failure mode of Groups A to D.

Slabs in group B1 and B2, which were strengthened by EB-CFL only, failed as CFL rupture near the midspan shown in Fig. 8b. The CFL strips at the two ends of CFL prevented the debonding, and the CFL ruptured brittlely. The midspan deflections of B1 and B2 specimens were larger than that of specimens in group A because the stiffness of CFL is smaller than that of steel plates. However, there were more cracks on the slabs strengthened by EB-CFL than those strengthened by SP (group A) and distributed more uniformly.

Specimens in group C, in which CFL and SP were installed separately and parallelly, failed in mixed characteristics as shown in Fig. 8c. CFL strips ruptured near the midspan and SP debonded from the end due to the damage of the anchoring bolts. The failure happened in a brittle manner. Additionally, shear failure also happened for specimen C-3 together with CFL rupturing and SP debonding. The shear failure mode of C-3 was similar to that of group A caused by the high stress concentration at the ends of steel plates. However, the failure location for specimen C-3 was different, which happened at a location near the ends of the steel plates but not at the ends because the CFL strips end-anchor bonded at the ends of CFL prevented shearing failure happened at those locations. Because CFL and SP were bonded separately, they resisted force alone. Therefore, the strengthened slabs in group $C$ failed as those with single EB strengthening technique.

Groups D1 and D2 strengthened by overlap configuration showed higher flexural strength and stiffness than others. Slabs of Group D1, which were strengthened by inner SP and outer CFL without CFL end-anchorage, failed from the end of the steel plates. The bolts were sheared break and steel plates debonded with a thin layer 
of concrete on the surface, as shown in Fig. 8d. CFL and SP were bonded in good condition and did not separate in the entire testing process. Because the inner steel plate was 3.7-mm-thick, it was difficult to use FRP anchor. Therefore, only steel bolts were used to anchor at the ends for this type of specimens. The brittle debonding happened from the end of SP which caused by the high stress concentration due to insufficient anchor at the end. How to design the bolts anchor to avoid the debonding failure is important in the hybrid strengthening technique, which will be addressed in the further research.

Slabs of group D2, which were strengthened by inner CFL with CFL strips as end-anchorage and outer SP, failed like an under-reinforced concrete flexural member. After some irregular sounds, the debonding happened from the interface between CFL-SP composite plate and concrete. Finally, concrete in the compressive zone crushed as shown in Fig. 8e. The CFL-SP did not totally separate from the slab because of the anchorage action of bolts. It should be noted that the interface bond between CFL and SP was not damaged until the whole specimen failure which proved the effectiveness of the anchorage technique. It indicated that CFL could be anchored successfully by the bolts when they were bonded to the steel plate. Moreover, CFL could resist tension force together with SP through the reliable bonding between CFL and SP.

\subsection{Load versus strain relationship}

Load versus stain relationships for internal tension steel, CFL and steel plate are reported and discussed in this section.

\subsection{Strain of internal tension steel bars}

The typical curves of load versus strain of internal tension steel bars (SB1 or SB2) at midspan section for each group are compared in Fig. 9. It shows that internal tension steel bars in the specimens yielded before the ultimate failure. The tension steel bars in groups B1 and B2 yielded at similar load (around $30 \mathrm{kN}$ ), which was only a little higher than that of control slabs. The yielding load (about $63 \mathrm{kN}$ ) for group A, C and D1 were much higher. This was due to the externally bonded steel plates, which increased the stiffness and reduced the deflection of the slabs. The tension steel bars in D2-3 yielded at about $90 \mathrm{kN}$ which means the slabs strengthened with inner CFL and outer SP had better performance. The different strain levels in tension steel bars can also be seen from the figure. It is obvious that the strains in the tension steel bars were lower in the specimens with hybrid strengthening than that with single EB-CFL when the applied load was same. The internal reinforce bar strain of strengthened slabs was reduced significantly which indicated the hybrid CFL-SP strengthening technique obtained larger rigidity, smaller deflection, and lower service stress level in the reinforcing steel bars.

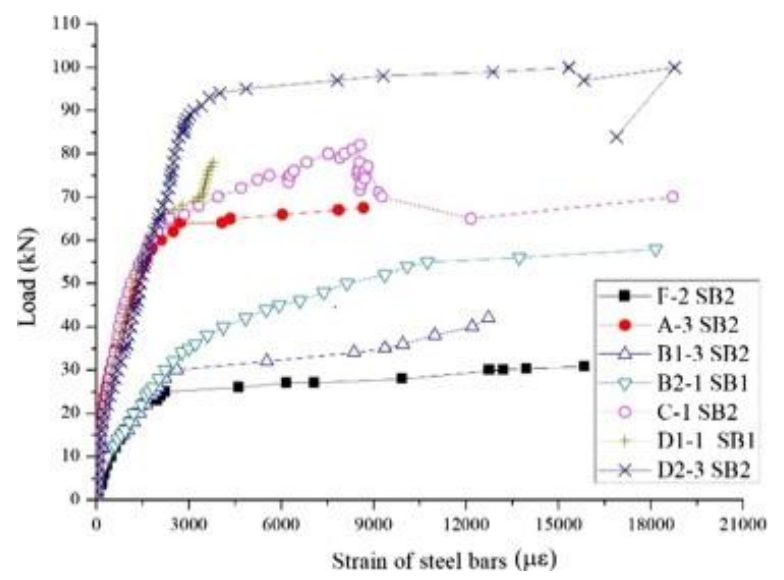

Fig. 9. Load versus stain of the internal steel bars curves for each group. 


\subsection{Strain on CFL}

The load versus CFL strain at midspan section relationships for all slabs strengthened with CFL are shown in Fig. 10. The curves are similar in the same group. Specimens in groups B1 and B2 were strengthened by CFL only and failed as CFL rupture. The maximum strains of CFL at the midspan in these specimens were around 10,000 $\mu \varepsilon$. The laminate ruptured at the location near the midspan of the specimen. There are two turning points in the curves which correspond to the initial concrete cracking and the internal tension steel yielding. Specimens in group $\mathrm{C}$, which were strengthened by both CFL and SP as parallel configuration, also failed as CFL rupture. The ultimate strain for C-3 was about 10,000 $\mu \varepsilon$. However, the ultimate strain in CFL in C-1 and C-2 were much lower because the CFL rupture did not happen at the middle section where strain measurement was taken. Specimens in group D1 failed as debonding of SP and CFL did not rupture. The maximum CFL strains were around $8000 \mu \varepsilon$, which was lower than the measured maximum strain of CFL $(10,000 \mu \varepsilon)$ used in groups B1, B2 and C. Fig. 10 showed that CFL ruptured at lower load for group B1, B2 due to low flexural rigidity and excessive deformation. Therefore, the high strength of CFL was not utilized efficiently by single EB-CFL strengthening. Compared to groups B1 and B2, the strains of CFL were relatively lower for groups C and D1 at the same load levels. Group D1 obtained higher flexural strength with lower strains in CFL by using over-lap configuration, which proves that the over-lap configuration hybrid strengthening technique had better strengthening effect than the strengthening of single EB-CFL and CFL-SP parallel configuration.

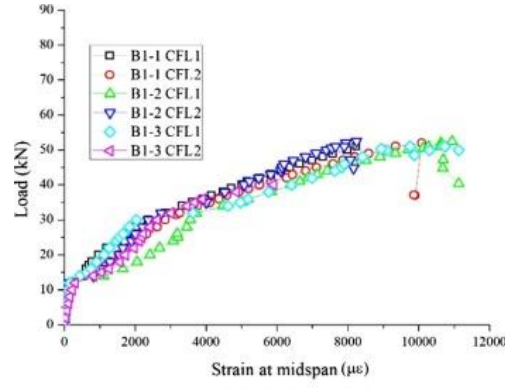

(a) Group B1

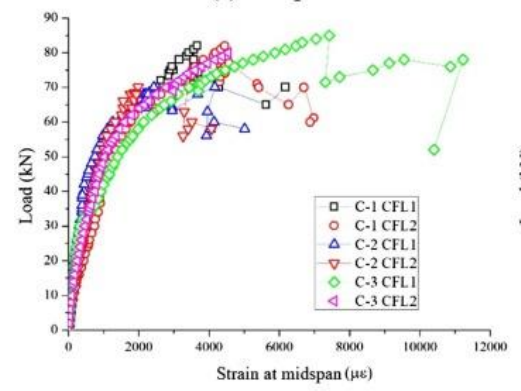

(c) Group C

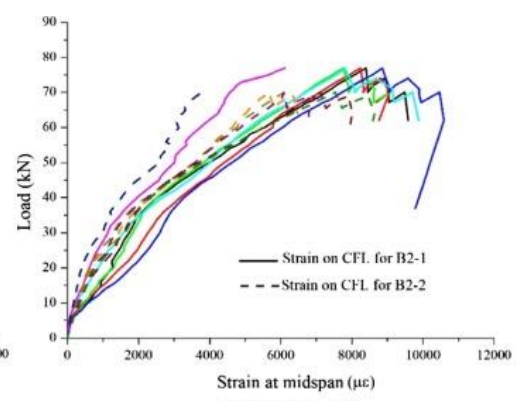

(b) Group B2

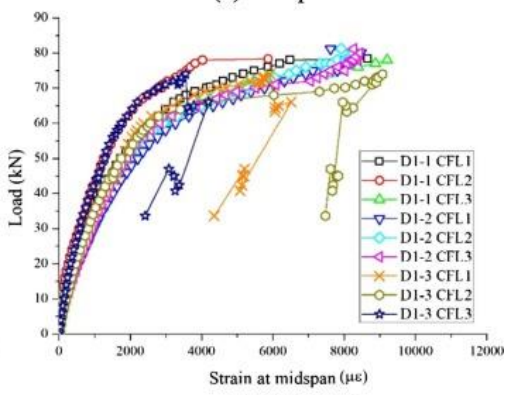

(d) Group D1

Fig. 10. Load versus strain on CFL at midspan relationship.

Specimens in group D2 were strengthened with inner CFL and outer SP. The SP applied compression on CFL due to the steel anchors. Therefore, it was not easy to use strain gage to measure the tensile strain of CFL. The average maximum strain of the outer SP was $13,623 \mu \varepsilon$. Although there might be some relative slip between the CFL-SP interface causing the tensile strain of CFL lower than that of SP, the CFL strain would not be too much smaller than that of SP and close to the measured maximum strain at the midspan $(10,000 \mu \varepsilon)$. This indicates that the high strength superiority of CFL can be utilized in a very high level in the CFL-SP hybrid strengthening technique. 


\subsection{Strain on steel plates}

The load versus steel plates' strain for slabs strengthened with SP and CFL-SP are shown in Fig. 11. For the specimens in group A bonded with SP only, most steel plates did not yield or just began to yield before failure as shown in Fig. 11a due to the sudden shear failure. The curves of Groups C and D2 (Fig. 11b and 11c) show stable yielding stage. Steel plates in Group D2 yielded at higher load than those in Group C. The average yielding load for Groups C and D2 were $44.2 \mathrm{kN}$ and $56.9 \mathrm{kN}$, respectively. Steel plates' strains of specimens in Groups $C$ and D2 during loading were compared in Fig. 11d. It is obvious that the CFL-SP hybrid strengthening technique utilized more material's strength by overlap-type configuration in Group D2, thus obtained higher flexural strength, stiffness and ductility than other slabs.

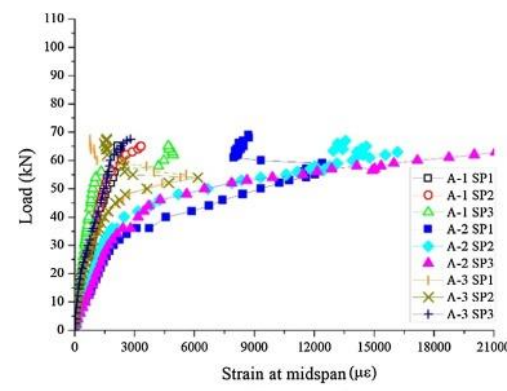

(a) group $\mathrm{A}$

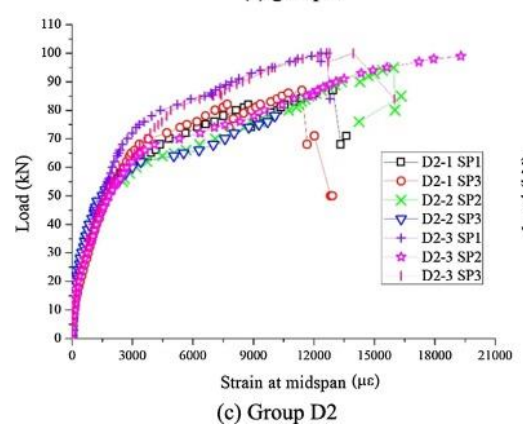

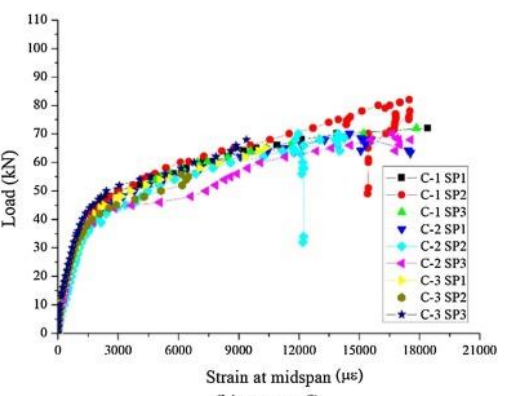

(b) group $\mathrm{C}$

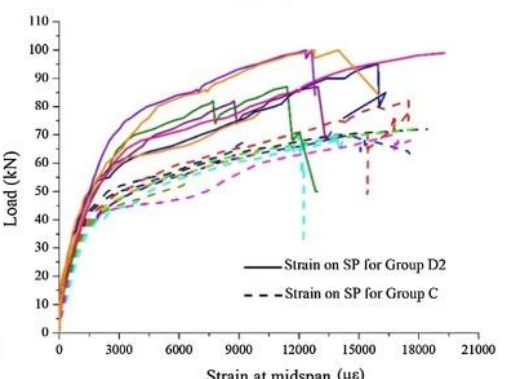

(d) Comparison between $\mathrm{C}$ and $\mathrm{D} 2$

Fig. 11. Load versus strain on SP at midspan relationship.

\subsection{Strains for the CFL-SP composite plate}

In order to clarify how CFL and steel plates worked together when both of them were used to strengthen the RC slabs, the strains of these two materials in groups $C$ and D are compared in Fig. 12.

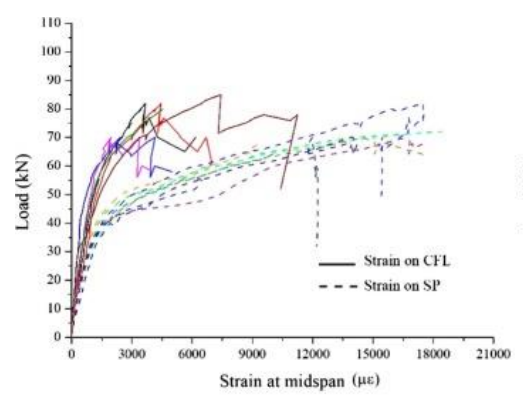

(a) group $\mathrm{C}$

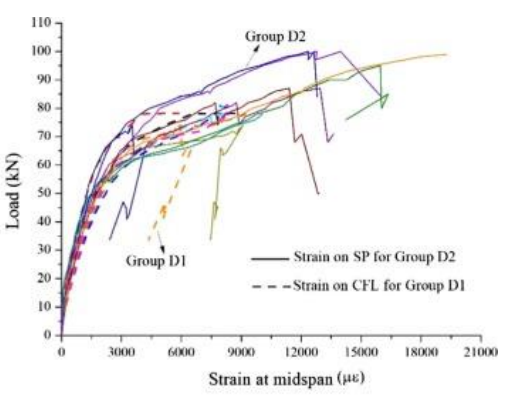

(b) group D

Fig. 12. Comparison for the strain on CFL and SP at the midspan.

Slabs in group $\mathrm{C}$ were strengthened by CFL and SP in parallel configuration. Fig. 12a shows that there was some difference between the strains of CFL and SP, and steel plate had larger strains than CFL, which indicates that SP played a leading role to resist tension. This was caused by the different anchor conditions. Steel plates were anchored by the bolts along the plates, while CFLs were only anchored by strips at the ends. Due to the different 
bonding mechanisms, the similar strains at the tension face of concrete were transferred by different ways to CFL and steel plates. For the EB-CFL, only epoxy adhesive on the concrete-CFL interface could transfer the shearing stress, and there was relative slip between adhesive and concrete. However, both steel bolts and adhesive for the EB-SP could transfer the interface stress, and the relative slip was less than that in the EB-CFL bonding interface. Therefore, these two materials had inconsistent deformations when they were bonded separately to the RC slab, and the strain on the CFL was less than that on the SP at the same load. Parallel configuration is not recommended for the hybrid strengthening technique when CFL is used together with SP. In order to efficiently utilize the high strength of both materials, CFL and SP should keep the deformation coordination condition to resist tensile stress together.

When bonded together as the overlap-type hybrid configurations, CFL and SP can work compositely due to the anchoring of the bolts and reliable interface bond between them. This was proved by the fact that the bond interface between CFL and SP was kept in good condition before failure. However, it was difficult to measure the strain for the inner layer material. Comparison between strains on the outer layer of CFL-SP composites were shown in Fig. 12b. Strains of steel plates in Group D2 were higher than that of CFL in Group D1. This was caused by the different anchors at the ends. For Group D1, there was only one steel bolt at the ends of SP and CFL, while there were CFL strips bonded at the ends of CFL for group D2. Debonding failure happened from plate ends in group D1, while at the middle of the slabs in group D2. Therefore, CFL strips bonded at the CFL ends helped to increase the ductility of the strengthened RC slabs. Consequently, this comparison further proves that hybrid strengthening technique including inner CFL with CFL strips anchor at ends and outer SP can achieve higher strength and ductility for the strengthened RC slab.

\subsection{Stiffness change and crack propagation}

The load versus deflection curves in Fig. 6, Fig. 7 show various effects on the flexural stiffness of the slabs when strengthened by different methods. In order to compare the results quantitatively, the stiffness of the slabs was defined as the slope of the line which connected the origin point and a point corresponding to a deflection of L/360 (where $L$ is the slab's span) in the load versus deflection curves [8]. It means that the stiffness of the slabs was defined as the slope of the load versus deflection curve when the slabs were in the linear stage. The stiffness results for each slab are listed in Table 3 and shown in Fig. 13. Compared to control slabs (Group F), the stiffness of all strengthened specimens increased except B1-1. The slabs strengthened with steel plates showed similar increase in flexural stiffness. The average increases for groups A, C, D1 and D2 were 83\%, 79\%, 89\%, and $91 \%$ over the control slab, respectively. The slabs strengthened by CFL had slight increase in stiffness over the control slabs. The average increase for Groups B1 and B2 were $5 \%$ and $11 \%$, respectively. This confirms the limitation of EB-FRP technique to increase stiffness.

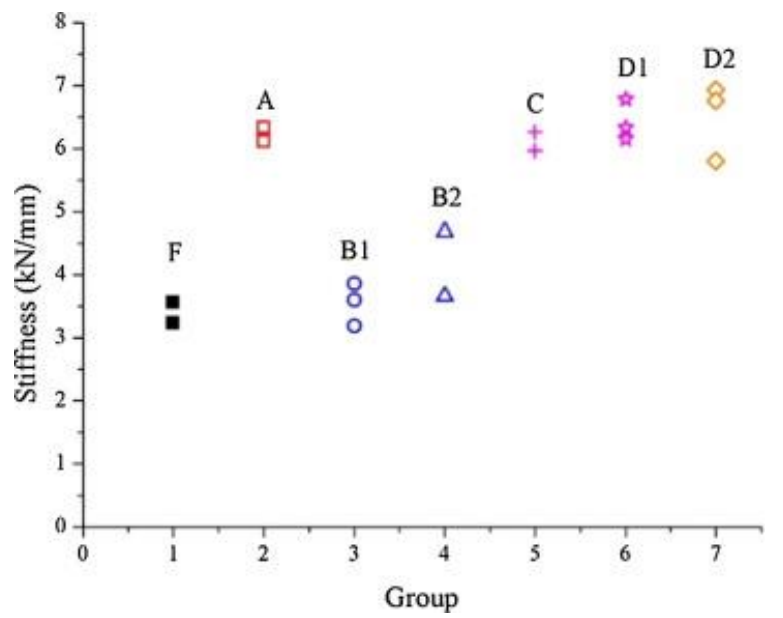

Fig. 13. Stiffness of each slab. 
The cracking load for each slab is also included in Table 3. The average cracking load for Groups B1, B2 and the control slabs were $18.7 \mathrm{kN}, 15.5 \mathrm{kN}$ and $9.0 \mathrm{kN}$, respectively. The slabs strengthened by SP and CFL-SP cracked at higher load with the same trend as stiffness change. The average cracking loads of Groups A, C, D1 and D2 were $29.3 \mathrm{kN}, 35.0 \mathrm{kN}, 32.7 \mathrm{kN}$ and $31.7 \mathrm{kN}$, respectively. It should be noted that it was not very accurate when the first crack was found by naked eyes.

Fig. 14 shows the relationship of load versus the width of the main crack. Compared to the control slabs, the width of crack for those strengthened slabs was smaller at the same load. The CFL-SP hybrid strengthening obviously provided the best effect of delaying the crack progress by the evidence of the highest cracking load, the least width of main crack at the same load, and the relatively lower rate of crack propagation.

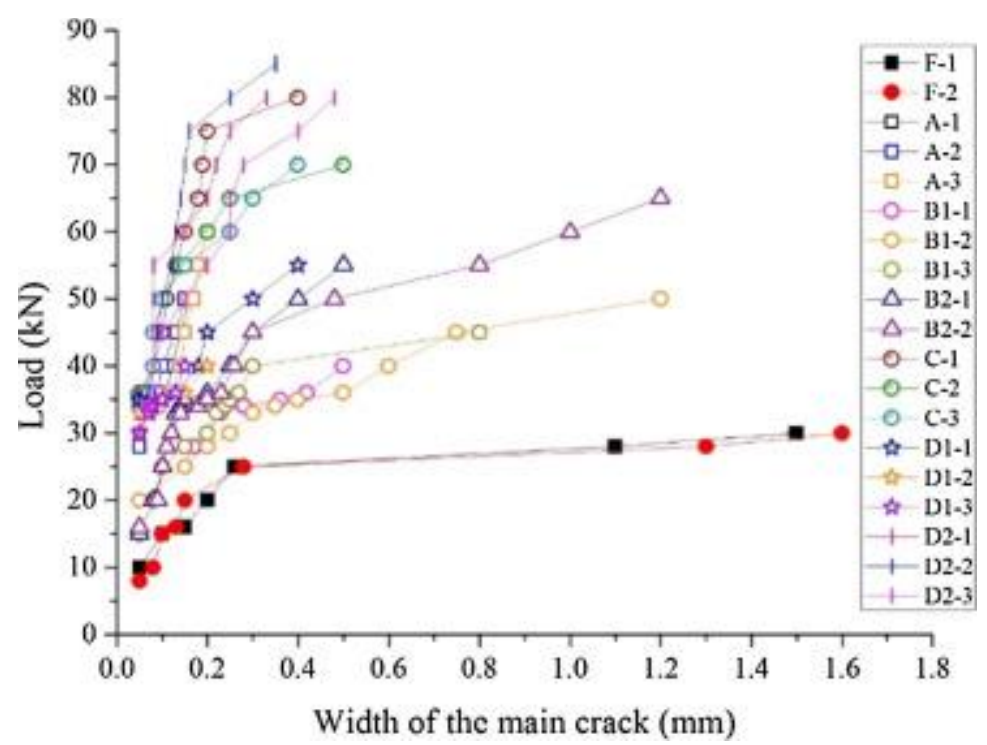

Fig. 14. Load versus width of the main crack relationship.

In this study, the flexural cracks in the slab bottom surface displayed similar pattern as cracks on the side. It is easier to observe the cracks development on the side surface. Therefore, only flexural cracks on the side surface were studied in this paper. However, other cracking features (e.g., debonding cracks) in the bottom surface may be different due to different strengthening materials. The crack features in the slab bottom surface will be studied in the future research.

\section{Conclusions}

An innovative hybrid strengthening technique combining carbon fiber laminates (CFL) and thin steel plate (SP) was proposed in this study to overcome the weakness of externally bonded strengthening method using single material. CFL and steel plate were compositely bonded at the same location and resisted tension together. In this hybrid strengthening system, steel plate ensured the ductility of the structure and enhanced its serviceability, whereas CFL contributed to load-carrying capacity and reduced the thickness of steel plate. The hybrid strengthening technique showed its effectiveness in enhancing the flexural strength and serviceability of the RC elements. It is worth to indicate that the corrosion of steel plate in the hybrid strengthening technique is a potential issue which may cause durability problem for the strengthened structures. Therefore, anti-rust measures (e.g., antirust coat) should be applied to the steel plates before and after they are applied to the structures in the practice. Although it needs similar anti-rust measures as those in the traditional pure steel 
plate strengthening, the hybrid strengthening has significant construction and strengthening benefits as discussed in this paper.

From the results of the experimental study on behavior of RC slabs strengthened with CFL-SP composites, the following conclusions can be drawn:

1) The CFL-SP hybrid strengthening technique was proved to be more effective than the single EB-strengthening technique. The highest average increase in flexural strength over the control slab was $204 \%$, which was $27.9 \%$ higher than that of the equivalent single CFL-strengthened slab. Moreover, the average flexural stiffness and it was $91 \%$ and $80 \%$ higher than those of the control slabs and the single CFL- strengthened slabs, respectively.

2) Using CFL strips bonding at the CFL ends and steel bolts with epoxy adhesive fastening the steel plates was proved as the most reliable anchor system for the hybrid strengthening with overlap configure (inner CFL and outer SP). The interface between CFL and steel plate did not separate until the failure of the strengthened slab. By using this anchor system, the high strength superiority of CFL can be utilized efficiently.

3) In the parallel hybrid configuration, SP played a leading role to resist tension when SP and CFL were bonded to concrete separately. When these two materials were combined in overlap configurations, the results showed better consistent deformation between CFL and SP. The overlap configuration with inner CFL and outer SP was proved to be the most effective hybrid strengthening technique. Strengthened slabs with this configuration achieved the highest flexural strength and stiffness, and displayed acceptable ductility before failure.

\section{Conflict of interest}

None.

\section{Acknowledgments}

The project was supported by National Key R\&D Program of China (No. 2017YFC0806000) and National Natural Science Foundation of China (No. 11627802, 51678249 and 11872185), Guangdong Province Natural Science Foundation of China (No. 2016A030310414), and Open project for key laboratory construction of Mountainous Bridges and tunnels in Chongqing Jiaotong University (No. CQSLBF-Y16-9).

Recommended articlesCiting articles (3)

\section{References}

[1] $\mathrm{ACl}$ 440.2R-17, Guide for the design and construction of externally bonded FRP systems for strengthening concrete structure, American Concrete Institute Farmington Hills, MI, USA, 2017

[2] ASTM, ASTM A706/A406M Standard specification for low-alloy steel deformed and plain bars for concrete reinforcement. West Conshohocken, PA, USA (2004)

[3] ASTM, ASTM D3039/D3039M Standard test method for tensile properties of polymer matrix composite materials. West Conshohocken, PA, USA (2000)

[4] G. Arslan, F. Sevuk, I. Ekiz, Steel plate contribution to load-carrying capacity of retrofitted RC beams. Constr. Build. Mater., 22 (3) (2008), pp. 143-153

[5] M.A. Alam, W. Mohammed, S. Bakkar, S. Beddu, Prevention of premature failures of plate bonded flexurally strengthened RC slab using end anchor and connector. Alexandria Eng. J., 57 (1) (2016)

[6] J.F. Bonacci, M. Maalej, Behavioral Trends of RC Beams Strengthened with Externally Bonded FRP. J. Compos. Constr., 5 (5) (2001), pp. 102-113 
[7] J.A. Barros, M. Rezazadeh, J.P. Laranjeira, M.R. Hosseini, M. Mastali, H. Ramezansefat, Simultaneous flexural and punching strengthening of RC slabs according to a new hybrid technique using U-shape CFRP laminates. Compos. Struct., 159 (2017), pp. 600-614

[8] M.J. Chajes, T.A.J. Thomson, T.F. Januszka, W.W.J. Finch, Flexural strengthening of concrete beams using externally bonded composite materials. Constr. Build. Mater., 8 (3) (1994), pp. 191-201

[9] G.M. Chen, Z. Zhang, Y.L. Li, X.Q. Li, C.Y. Zhou, T-section RC beams shear-strengthened with anchored CFRP U-strips. Compos. Struct., 144 (2016), pp. 57-79

[10] J.F. Chen, S.T. Smith, L. Lam, J.G. Teng, Behaviour and strength of FRP-strengthened RC structures: a stateof-the-art review. Struct. Build., 156 (1) (2003), pp. 51-62

[11] GB 50010-2010, Code for design of concrete structures, China Architecture \& Building Press, 2010.

[12] S.V. Grelle, L.H. Sneed, Review of Anchorage Systems for Externally Bonded FRP Laminates. Int. J. Concr. Struct. Mater., 7 (1) (2013), pp. 17-33

[13] B. Gao, C.K. Leung, J.K. Kim, Prediction of concrete cover separation failure for RC beams strengthened with CFRP strips. Eng. Struct., 27 (2) (2005), pp. 177-189

[14] P.Y. Huang, J.C. Zeng, Carbon fiber laminate and application, " The invention patent authorization number: ZL200410026742.8, China, Date of authorization proclamation: 2006-8-23, 2006

[15] A.S.A. Jabbar, M.A. Alam, K.N. Mustapha, Investigation of the effects of connectors to enhance bond strength of externally bonded steel plates and CFRP laminates with concrete. Steel Composite Struct., 20 (6) (2016), pp. 1275-1303

[16] R. Jones, R.N. Swamy, A. Charif, Plate separation and anchorage of reinforced concrete beams strengthened by epoxy-bonded steel plates. The Structural Engineer, 66 (5) (1988), pp. 85-94

[17] R. Kalfat, R. Al-Mahaidi, Investigation into bond behaviour of a new CFRP anchorage system for concrete utilising a mechanically strengthened substrate. Compos. Struct., 92 (11) (2010), pp. 2738-2746

[18] I.F. Kara, A.F. Ashour, M.A. Köroğlu, Flexural behavior of hybrid FRP/steel reinforced concrete beams. Compos. Struct., 129 (2015), pp. 111-121

[19] R. L'Hermite, Use of bonding techniques for reinforcing concrete and masonry structures. Matériaux Et Construction, 10 (2) (1977), pp. 85-89

[20] X.J. Li, Y.Y. Lu, N. Li, Behavior of Two-way RC Slabs Combination Strengthened with CFRP Strips and Steel Sheets. Appl. Mech. Mater., 501-504 (2014), pp. 1048-1052

[21] G.C. Mays, K.D. Raithby, Bonded external reinforcement for strengthening concrete bridges, Report for Transport \& Road Research Laboratory by University of Dundee, 1986.

[22] M.D. Mcdonald, The flexural performance of $3.5 \mathrm{~m}$ concrete beams with various bonded external reinforcements, Publication of Transport \& Road Research Laboratory, 1982.

[23] U. Meier. Strengthening of structures using carbon fibre/epoxy composites. Constr. Build. Mater., 9 (9) (1995), pp. 341-351

[24] T. Mohammadi, B. Wan, K.A. Harries, M.E. Sweriduk, Bond behavior of FRP/concrete in presence of intermediate crack debonding failure. J. Compos. Constr., 21(5), paper 04017018 (2017), p. 12

[25] T. Mohammadi, B. Wan, K.A. Harries, Bond-slip behavior of fiber-reinforced polymer/concrete interface in single shear pull-out and beam tests. J. Reinf. Plast. Compos., 35 (5) (2015), pp. 375-386

[26] S.A.A. Mustafa, H.A. Hassan, Behavior of concrete beams reinforced with hybrid steel and frp composites, Hbrc J., 2017, in press.

[27] Z. Ouyang, B. Wan, An Analytical Model of FRP-Concrete Bond Deterioration in Moist Environment. Adv. Struct. Eng., 12 (6) (2009), pp. 761-769

[28] S.M. Rakgate, M. Dundu, Strength and ductility of simple supported $\mathrm{r} / \mathrm{c}$ beams retrofitted with steel plates of different width-to-thickness ratios. Eng. Struct., 157 (2018), pp. 192-202

[29] A.E. Refai, F. Abed, A. Al-Rahmani, Structural performance and serviceability of concrete beams reinforced with hybrid (gfrp and steel) bars. Constr. Build. Mater., 96 (2015), pp. 518-529 
[30] M. Rezazadeh, J.A. Barros, H. Ramezansefat, End concrete cover separation in RC structures strengthened in flexure with NSM FRP: Analytical design approach. Eng. Struct., 128 (2016), pp. 415-427

[31] S.T. Smith, S. Hu, S.J. Kim, R. Seracino, FRP-strengthened RC slabs anchored with FRP anchors. Eng. Struct., 33 (4) (2011), pp. 1075-1087

[32] R.N. Swamy, R. Jones, J.W. Bloxham, Structural behaviour of reinforced concrete beams strengthened by epoxy bonded steel plates. The Structural Engineer, 65 (2) (1987), pp. 59-68

[33] H.H. Thomsen, Failure mode analy [s] is of reinforced concrete beams strengthened in flexure with externally bonded fiber reinforced polymers. J. Compos. Constr., 8 (2) (2004), pp. 123-131

[34] J.G. Teng, J.F. Chen, FRP-strengthened RC structures. Wiley, Chichester (2002)

[35] Z.M. Wu, C.H. Hu, Y.F. Wu, J.J. Zheng, Application of improved hybrid bonded FRP technique to FRP debonding prevention. Constr. Build. Mater., 25 (6) (2011), pp. 2898-2905

[36] R. Zarnic, S. Gostic, V. Bosiljkov, V. Bokan-Bosiljkov, Improvement of bending load-bearing capacity by externally bonded plates. Creating with Concrete, Thomas Telford, London (1999), pp. 433-442

[37] D. Zhang, X. Gu, Q. Yu, H. Huang, B. Wan, C. Jiang, Fully probabilistic design of FRP-to-concrete bonded joints considering model uncertainty. Compos. Struct., 185 (2018), pp. 786-806

[38] X.H. Zheng, P.Y. Huang, G.M. Chen, X.M. Tan, Fatigue behavior of FRP-concrete bond under hygrothermal environment. Constr. Build. Mater., 95 (2015), pp. 898-909

[39] X.H. Zheng, P.Y. Huang, Q. Han, G.M. Chen, Bond behavior of interface between CFL and concrete under static and fatigue load. Constr. Build. Mater., 52 (2014), pp. 33-41 